\title{
INTRODUCTION BY CHAIRMAN OF ASTIN
}

Copenhagen, December, I958

On behalf of the Committee of Astin I am very happy to be privileged to express a hearty welcome to readers of this first bulletin.

The aims of the Astin section of the Permanent Committee for International Actuarial Congresses, as expressed in the rules, are the promotion of actuarial studies in general insurance.

There is no doubt that events of recent years have demonstrated an increasing need for international contact in these fields. Technical actuarial questions are much the same in the various parts of the world, but with only a few actuaries engaged in the business of general insurance, contacts have necessarily been very limited. The establishment of a means for regular exchange of ideas on an international basis will, I sincerely hope, provide opportunities for stimulation in our researches in the years to come.

The success of the young Astin section cannot, of course, depend solely on the activity of its committee, although each of us appointed in New York will be doing his best to further the aims of the section. An editorial committee comprising renowned colleagues from various countires will help our editor in his work, but to ensure a full measure of success the initiative and collaboration of each individual member is necessary.

The early years when the plans for our future work are being evolved will, of necessity, be difficult and any suggestions from our members will be carefully considered by the committee. In particular we shall be greatly helped if members will let us know of any particular activity in which they are interested or engaged by completing the form enclosed with the bulletin.

A first essential in promoting collaboration is to know and understand each other. Views can be exchanged through the official channel of the Astin bulletin or directly between members. Inevitably language difficulties will complicate the proper understanding of the background of each others problems and it will clearly be of advantage to convey ideas in one of the official 
languages of the International Actuarial Congresses. The use of either French or English would appear to minimise these difficulties for the majority of members.

It is my sincere hope that the interchange of ideas will result in the establishment of many friendly relationships, thus promoting not only our own specialised studies but also the understanding and friendship between nations.

Paul Johansen 